\title{
Interação genótipo $\times$ ambiente em codornas de postura alimentadas com rações com dois níveis de energia metabolizável ${ }^{1}$
}

\section{Priscilla Cristina Georg ${ }^{2}$, Emilia de Paiva ${ }^{2}$, Ana Carolina Müller Conti ${ }^{2}$, Elias Nunes Martins ${ }^{3}$, Eliane Gasparino ${ }^{3}$, Alexandre Leseur dos Santos ${ }^{2}$}

\footnotetext{
1 Projeto financiado pelo CNPq.

2 Pós-Graduação UEM - Universidade Estadual de Maringá.

${ }^{3}$ Departamento de Zootecnia - UEM.
}

RESUMO - Foram coletados dados de peso do ovo, altura de albúmen, espessura da casca, peso corporal e produção total de ovos aos 90 dias de postura de três linhagens de codornas de postura (Coturnix coturnix japonica) alimentadas com rações contendo 2.900 ou 2.500 kcal de energia metabolizável para verificar a existência da interação genótipo $\times$ ambiente. Utilizou-se o programa computacional MTGSAM, que permite inferência bayesiana, usando amostragem de Gibbs, aplicado a um modelo animal, para estimar os componentes de covariâncias, herdabilidade e correlações genéticas entre os dois ambientes. Por meio dos resultados de herdabilidade e correlações genéticas, concluiu-se que houve interação genótipo $\times$ ambiente somente para as características altura de albúmen e espessura da casca. As características peso do ovo e peso corporal são passíveis de ganhos genéticos, independentemente do nível de energia da ração, enquanto a produção de ovos tem baixo potencial para ganhos genéticos se a seleção for baseada em recordes parciais.

Palavras-chave: altura de albúmen, espessura da casca, herdabilidade, peso corporal, peso do ovo, produção de ovos

\section{Genotype-environment interaction in laying quail fed diet with two levels of metabolizable energy}

\begin{abstract}
Data of egg weight, albumen height, shell thickness, body weight and egg production at 90 days of laying from three lines of laying quails (Coturnix coturnix japonica), fed diets with 2,900 kcal or 2,500 kcal metabolizable energy, were used to check the existence of the genotype-environmental interaction. The MTGSAM software program was used, which allows Bayesian inference, using the Gibbs Sampling, applied to an animal model, to estimate the co-variance components, heritability and genetic correlation between both environments. The results of heritability and genetic correlations showed that there was a genotype-environment interaction only for albumen height and shell thickness. The traits egg weight and body weight are susceptible to genetic gains regardless of the diet energy level, while egg production has low potential for genetic gains if the selection is based on partial records.
\end{abstract}

Key Words: albumen height, body weight, egg production, egg weight, heritability, shell thickness

\section{Introdução}

A criação de codornas de postura tem como principal objetivo a produção de ovos, um produto muito apreciado pelos consumidores e com boas qualidades nutricionais. De acordo com o National Research Council (1994), as rações para codornas devem conter $24 \%$ de proteína bruta (PB) para aves em crescimento, 20\% de PB para aves em postura e $2.900 \mathrm{kcal}$ de energia metabolizável (EM). Essas informações, no entanto, são antigas e nem sempre estão de acordo com o potencial genético do animal e com seu ambiente de criação.
A estimação das características qualitativas do ovo é importante para os processos de seleção e melhoramento genético, que podem ser conduzidos de forma a atender às necessidades do criador ou do consumidor.

Os métodos indicados para estimação dos componentes de covariância já estão relativamente bem definidos (Gianola \& Fernando, 1986) e as estimativas podem variar de acordo com a população e com o ambiente em que os indivíduos são criados. Todavia, se os filhos são criados em condições de ambiente diferentes daquelas em que os pais foram selecionados, o resultado da seleção dependerá da magnitude da correlação entre os valores genéticos 
expressos nos dois ambientes. Ou seja, para que o processo de seleção seja feito de maneira eficiente, é necessário quantificar se há interação genótipo × ambiente, uma vez que genótipos superiores em determinados ambientes podem não o ser em outros. Assim, frequentemente o efeito do genótipo no desempenho do animal depende das circunstâncias ambientais a que o animal está sujeito.

De acordo com Falconer (1987), uma característica em ambientes diferentes pode ser interpretada como sendo características diferentes, pois os genes que a controlam em determinado ambiente podem ser diferentes, pelo menos parcialmente, daqueles que a controlam em outro.

Assim, verificou-se neste trabalho a existência de interação genótipo $\times$ ambiente no desempenho de três linhagens de codornas de postura criadas em ambientes de 2.900 ou 2.500 kcal de energia metabolizável.

\section{Material e Métodos}

O experimento foi desenvolvido no setor de coturnicultura da Fazenda Experimental de Iguatemi, pertencente à Universidade Estadual de Maringá, no período de julho de 2006 a janeiro de 2007.

Foram utilizadas três linhagens de codornas de postura, denominadas L1, L2 e L3. As aves em experimento foram obtidas por meio de acasalamento controlado, na relação de um macho para duas fêmeas. Foram realizadas incubações em dois períodos, com intervalo de uma semana, de modo que, após as eclosões, as aves foram diferenciadas em primeira e segunda eclosão. Os ovos foram identificados por pai e mãe, possibilitando a anotação da genealogia da ave após eclosão, quando foram anilhados e criados até os 28 dias de vida em piso com cama, recebendo ração para crescimento conforme recomendações do NRC (1994).

Aos 28 dias de idade, as aves foram separadas por sexo. As fêmeas foram alojadas em gaiolas individuais, divididas em dois grupos, de forma que cada matriz teve filhas nos dois grupos. Cada grupo passou a ser alimentado com um dos tipos de ração (Tabela 1). Os termos "ambiente 1" e "ambiente 2", ou nível "normal” e "baixo", foram denominados para as aves alimentadas com rações contendo 2.900 e $2.500 \mathrm{kcal}$ de energia metabolizável/kg de ração, respectivamente.

As aves, em número de 163 e 145 na linhagem 1, 186 e 188 na linhagem 2, e 201 e 177 na linhagem 3, alimentadas respectivamente com as rações 1 e 2 , tiveram sua produção de ovos monitorada diariamente até os 90 dias de produção, contados a partir do primeiro ovo em cada lote (linhagem/ eclosão). A produção total de ovos foi expressa em
Tabela 1 - Composição das rações experimentais

\begin{tabular}{lcc}
\hline Item & Ração 1 & Ração 2 \\
\hline Energia metabolizável kcal/kg & 2.900 & 2.500 \\
Proteína bruta (\%) & 22,00 & 22,00 \\
Fibra bruta (\%) & 3,28 & 3,78 \\
Cálcio (\%) & 2,50 & 2,50 \\
Fósforo disponível (\%) & 0,36 & 0,36 \\
Lisina total (\%) & 1,21 & 1,21 \\
Metionina + cistina total (\%) & 0,75 & 0,75 \\
Sódio (\%) & 0,18 & 0,18 \\
\hline Ingrediente (\%) & Ração 1 & Ração 2 \\
\hline Milho grão & 50,83 & 48,855 \\
Soja farelo & 38,62 & 36,159 \\
Trigo farelo & 0,0 & 7,601 \\
Calcário & 5,29 & 5,342 \\
Óleo de soja & 3,16 & 0,00 \\
Fosfato bicálcico & 1,33 & 1,24 \\
Sal comum & 0,35 & 0,347 \\
Vitpos-ave & 0,252 & 0,252 \\
DL-metionina & 0,075 & 0,073 \\
Min-aves & 0,068 & 0,068 \\
L-lisina HCl & 0,016 & 0,048 \\
Antioxidante ${ }^{1}$ & 0,01 & 0,01 \\
\hline 1 Beta hidroxi tolueno. & &
\end{tabular}

${ }^{1}$ Beta hidroxi tolueno.

porcentagem de ovos postos no período de 90 dias. Aos 70 , 100 e 130 dias de idade, as aves foram pesadas e os ovos de cada fêmea foram coletados, anotando-se o peso, a altura de albúmen e a espessura da casca. Os ovos foram pesados em balança analítica com precisão de 0,01 g e, após as pesagens, foram quebrados. As cascas foram lavadas, identificadas e submetidas à secagem em temperatura ambiente. A espessura da casca foi obtida por meio de um micrômetro digital da marca Mitutoyo, modelo PK-0505, com precisão de $\pm 0,02 \mathrm{~mm}$, determinada na região média de cada lado da casca. A altura de albúmen (mm) foi obtida por meio de um micrômetro digital adaptado, posicionado próximo à gema.

Foram feitas análises unicaracteres, considerando os ambientes 1 e 2 características diferentes. Para as análises de peso do ovo, altura de albúmen e espessura da casca, foram considerados os efeitos de ambiente permanentes. Para produção total de ovos e para peso corporal, o mesmo não foi considerado.

Verificou-se um total de 467 animais na matriz de parentesco para a linhagem 1; 580 para a linhagem 2; e 574 para a linhagem 3.

As estimações dos componentes de variância genética aditiva, de ambiente permanente e residual foram feitas por meio do sistema computacional MTGSAM (Multiple Trait Gibbs Sampler in Animal Model) (Van Tassel \& Van Vleck, 1995), que permite a inferência Bayesiana, usando amostragens de Gibbs, aplicado ao modelo animal a seguir. 


$$
\mathrm{y}=\mathrm{X} \beta+\mathrm{Z}_{1} \mathrm{a}+\mathrm{Z}_{2} \mathrm{p}+\mathrm{e}
$$

em que: $\mathrm{y}=$ vetor de observações; $\mathrm{X}=$ matriz de incidência dos efeitos fixos contidos no vetor $\beta$, definidos como eclosão (1 e 2) e idade (70, 100 e 130 dias). Para produção total de ovos e peso corporal, a idade não foi considerada efeito fixo; $Z_{1}=$ matriz de incidência dos valores genéticos contidos no vetor $a$; $a=$ vetores dos efeitos genéticos diretos associados ao vetor $\mathrm{y} ; \mathrm{Z}_{2}=$ matriz de incidência dos efeitos permanentes contidos no vetor $\mathrm{p} ; \mathrm{p}=$ vetores dos efeitos ambientais permanentes associados ao vetor $\mathrm{y}$; e = vetor de erros aleatórios associado ao vetor Y.

Foi admitida a seguinte distribuição conjunta para $y$, $a, p$ e $e$ :

$$
\left[\begin{array}{c}
y \\
a \\
p \\
e
\end{array}\right] \sim\left\{\left[\begin{array}{c}
\mathrm{X} \beta \\
0 \\
0 \\
0
\end{array}\right] ;\left[\begin{array}{cccc}
V & Z_{1} G & Z_{2} P & R \\
G Z_{1}^{\prime} & G & \phi & \phi \\
P Z_{2}^{\prime} & \phi & P & \phi \\
R & \phi & \phi & R
\end{array}\right]\right\}
$$

em que: $\mathrm{V}=$ matriz de variância e covariância das observações, determinada por $\mathrm{Z}_{1} \mathrm{GZ}_{1}{ }^{\prime}+\mathrm{Z} 2 \mathrm{PZ}_{2}{ }^{\prime}+\mathrm{R} ; \mathrm{G}=$ matriz de variância e covariância genética aditiva determinada por $\mathrm{G}=\mathrm{G}_{0} \otimes \mathrm{A}$, de modo que $\mathrm{A}=$ matriz de coeficientes de parentescos; $\otimes=$ produto de Kronecker; e $\mathrm{G}_{0}=$ matriz de variância e covariância genética aditiva entre as características, como segue:

$$
G_{0}=\left[\begin{array}{cc}
\sigma_{a 1}^{2} & \sigma_{a 1 a 2} \\
\sigma_{a 1 a 2} & \sigma_{a 2}^{2}
\end{array}\right]
$$

em que: $\sigma_{a_{i}}^{2}=$ variâncias genéticas aditivas, em que $i$ indica a característica se peso do ovo, altura de albúmen, espessura da casca, produção total de ovos e peso corporal; $\sigma_{a_{i} a_{j}}=$ covariâncias genéticas, em que $i$ e $j$ indicam as características entre peso do ovo, altura de albúmen, espessura da casca, produção total de ovos e peso corporal; $P=$ matriz de covariância dos efeitos permanentes dado por, $P=I . \sigma_{p}^{2}$, em que $I$ uma matriz identidade; e $\sigma_{p}^{2}=$ componente de variância do efeito permanente.

$$
P_{0}=\left[\begin{array}{cc}
\sigma_{p 1}^{2} & 0 \\
0 & \sigma_{p 2}^{2}
\end{array}\right]
$$

$\mathrm{R}=$ matriz de variância residual, na qual I é uma matriz identidade e $\sigma_{e}^{2}$, o componente de variância residual.

$$
R_{0}=\left[\begin{array}{cc}
\sigma_{e 1}^{2} & 0 \\
0 & \sigma_{e 2}^{2}
\end{array}\right]
$$

Para aplicação do amostrador de Gibbs, admitiu-se distribuição plana para a esperança de $y$, normal para os efeitos genético aditivo direto, ambiental permanente e para os resíduos. Para as matrizes de covariância genética, admitiu-se distribuição de Wishart Invertida (IW), enquanto para os componentes de variância ambiental permanente e residual admitiu-se distribuição Gama Inversa.

Uma cadeia de Gibbs foi gerada para cada característica e cada linhagem, as quais foram submetidas ao teste de convergência por meio do teste de diagnóstico de Heidelberger \& Welch, disponíveis no CODA (Convergence Diagnosis and Output Analysis), implementado no programa R (2004). Como foi aplicado o teste de convergência, o número de ciclos na cadeia de Gibbs variou de 3.100.000 a 40.100.000, de onde amostras foram retiradas a cada 1.000 ciclos, após eliminação dos 100.000 ciclos iniciais. Assim, foram obtidas amostras de variaram de 3.000 a 40.000 componentes de covariâncias para cada linhagem.

Por meio das amostras dos componentes de variância, foram obtidas as estimativas de herdabilidades e correlações genéticas aditivas. A interação genótipo $\times$ ambiente foi avaliada por meio da verificação das correlações genéticas entre os ambientes 1 e 2 . Para valores de correlação próximos de um (1), foi descartada a presença de interação, visto que para essa característica os mesmos genes estariam se expressando nos dois ambientes. Valores de correlação menores caracterizam a presença de interação genótipo × ambiente onde apenas parte dos genes se expressam da mesma forma nos dois ambientes.

Paralelamente, os dados de produção de ovos foram analisados por meio do método de quadrados mínimos, considerando os efeitos de linhagem, nível de energia metabolizável, eclosão e suas interações, para comparar as médias de produção das linhagens nas duas situações. Quando a interação linhagem × nível de energia metabolizável foi significativa, procedeu-se à análise dos efeitos de nível de energia metabolizável dentro de cada linhagem e das linhagens dentro dos níveis de energia metabolizável.

\section{Resultados e Discussão}

As médias dos componentes de variância genética aditiva para peso do ovo variaram de 0,312 a 0,493 nas aves das três linhagens alimentadas com rações contendo 2.500 e 2.900 kcal de energia metabolizável.

Para a característica altura de albúmen, os valores foram de 0,165 a 0,198 para o componente de variância genética aditiva. Na linhagem 1 , a redução da energia da ração provocou aumento do componente de variância residual, o que indica aumento da sensibilidade ao ambiente.

As médias dos componentes de variância genética aditiva para espessura da casca foram de 0,0022 a 0,1153. Neste caso, a redução de energia na ração provocou maior variabilidade genética aditiva na linhagem 2 e praticamente 
a eliminou na linhagem 3. Para a produção de ovos, as médias dos componentes de variância foram de 0,011 a 28,942. A redução na energia da ração não provocou alterações nos componentes de variância genética aditiva das linhagens 1 e 2, mas promoveu forte elevação nesse componente na linhagem 3 , indicando que as aves dessa linhagem, quando criadas em condições de alimentação com baixa densidade energética, podem ter sua produção de ovos melhorada com base na seleção. Para o componente de variância residual da produção de ovos, a alteração observada ocorreu na linhagem 2, cujo componente aumentou quando as aves foram alimentadas com ração de baixa energia, o que comprova a sensibilidade desta linhagem ao ambiente.

A redução no nível de energia da ração não teve efeito sistemático sobre a magnitude dos componentes de variância do peso corporal.

As estimativas de herdabilidade encontradas para peso do ovo são consideradas de média a alta (Tabela 2) e estão dentro ou muito próximas dos valores reportados por Minvielle (1998) e Mielenz et al. (2004), que oscilam entre 0,35 e 0,66. Também estão próximas dos valores relatados por Özdemir \& Aksit (2004), que encontraram resultados de herdabilidade de 0,48 ao utilizarem dados de peso de ovo medido em várias idades, porém sem considerar efeito permanente.

A redução da energia da ração provocou diminuição da herdabilidade do peso do ovo na linhagem 1, mas não ocasionou alterações nesse parâmetro nas linhagens 2 e 3. Contudo, há possibilidade de resposta à seleção para peso do ovo nas três linhagens em ambas as situações.

Os coeficientes de correlação genética entre peso dos ovos em aves das três linhagens alimentadas com rações de 2.900 ou $2.500 \mathrm{kcal}$ de energia metabolizável foram relativamente altos e positivos e indicam pouca importância da interação genótipo $\times$ ambiente. A herdabilidade da altura de albúmen apresentou o mesmo comportamento do peso do ovo: diminuiu com a redução da energia da ração na linhagem 1, porém sem alterações nas linhagens 2 e 3 . As estimativas obtidas são próximas dos valores reportados por Özdemir \& Aksit (2004), que encontraram herdabilidade de 0,30 .

Os coeficientes de correlação genética entre as alturas de albúmen dos ovos de aves das três linhagens alimentadas com os dois tipos de rações foram medianos e positivos, evidenciando interação genótipo $\times$ ambiente.

A estimativa de herdabilidade para espessura da casca do ovo na linhagem 1 não se alterou com a redução do nível de energia na ração. Contudo, na linhagem 2, o menor nível de energia da ração causou grande redução da herdabilidade, enquanto na linhagem 3 , houve forte acréscimo, comprovando que as linhagens expressam seu material genético de formas diferentes dependendo do nível energético oferecido na ração.

As correlações genéticas para espessura da casca foram muito baixas, evidenciando a presença de interação genótipo × ambiente. Neste caso, é provável que, se aves selecionados em ambiente de criação normal (ração de 2.900 kcal de EM) tiverem seus filhos criados em ambiente de baixa energia, ou vice-versa, esses filhos não terão o mesmo desempenho dos pais, para essa característica.

As estimativas de herdabilidade para produção de ovos foram muito baixas, independentemente do nível de energia na ração, o que pode estar relacionado à seleção praticada nessas linhagens com base na produção de ovos na fase inicial de postura, provocando redução da variabilidade genética entre os animais. Dessa forma, as

Tabela 2 - Herdabilidades e correlações genéticas para peso do ovo, altura de albúmen, espessura da casca e produção total de ovos nos ambientes 1 e 2 em três linhagens de codornas de postura

\begin{tabular}{|c|c|c|c|c|}
\hline Característica & Linhagem & Herdabilidade ambiente 1 & Herdabilidade ambiente 2 & Correlação genética \\
\hline \multirow[t]{3}{*}{ Peso do ovo } & 1 & 0,66 & 0,45 & 0,85 \\
\hline & 2 & 0,52 & 0,59 & 0,81 \\
\hline & 3 & 0,51 & 0,56 & 0,84 \\
\hline \multirow[t]{3}{*}{ Altura do albúmen } & 1 & 0,33 & 0,20 & 0,41 \\
\hline & 2 & 0,29 & 0,31 & 0,46 \\
\hline & 3 & 0,28 & 0,29 & 0,47 \\
\hline Espessura da casa & 3 & 0,01 & 0,43 & 0,02 \\
\hline \multirow[t]{3}{*}{ Produção total } & 1 & 0 & 0 & 0,07 \\
\hline & 2 & 0 & 0 & 0,08 \\
\hline & 3 & 0,01 & 0,11 & 0,16 \\
\hline
\end{tabular}

Ambientes 1 e 2: aves alimentadas com rações contendo 2.900 e 2.500 kcal de energia metabolizável, respectivamente. 
estimativas de herdabilidade encontradas são diferentes das reportadas na literatura, cujos valores estão entre 0,21 e 0,39 (Minvielle, 1998; Mielenz et al., 2004).

A linhagem 3 foi a que apresentou maior variabilidade para produção de ovos, que foi mais evidente no ambiente 2 , ou seja, em condições de restrição energética, há maior diferenciação genética entre as aves, o que possibilita a seleção.

Da mesma forma que para a herdabilidade, as estimativas de correlação genética para produção de ovos foram muito baixas e não permitem concluir acerca da existência da interação genótipo $\times$ ambiente, uma vez que não houve variabilidade.

Os dados de produção de ovos (Tabela 3), analisados pelo método dos quadrados mínimos, mostraram que houve interação significativa $(\mathrm{P}<0,01)$ somente entre linhagem e nível de energia da ração. As aves alimentadas com as dietas com $2.900 \mathrm{kcal}$ de EM/kg de ração apresentaram maior produção de ovos, entretanto, o desdobramento da interação mostrou que na linhagem 1 a produção de ovos não foi alterada pelo nível de energia metabolizável da ração, enquanto nas linhagens 2 e 3 a produção reduziu quando alimentados com a ração de menor densidade energética.

As herdabilidades para os pesos corporais (Tabela 4), de modo geral, foram maiores nas linhagens 1 e 2 quando as aves foram alimentadas com ração de nível energético normal (2.900 kcal), enquanto, na linhagem 3, os valores foram muito próximos nos dois ambientes.

Os valores de herdabilidade da linhagem 3 e alguns valores da linhagem 2 são maiores que os encontrados na literatura, em torno de 0,42 a 0,74 (Minvielle, 1998; Mielenz et al., 2004). No entanto, as linhagens 1 e 2 praticamente se enquadram nessas estimativas. As estimativas de correlações entre os ambientes foram altas, o que indica ausência de interação genótipo $\times$ ambiente para o peso corporal.

Tabela 3 - Média percentual para produção total de ovos aos 90 dias de postura em cada linhagem e nível de energia metabolizável

\begin{tabular}{lccc}
\hline & \multicolumn{2}{c}{ Nível de energia metabolizável $(\mathrm{kcal} / \mathrm{kg}$ de ração) } & Média geral \\
\cline { 2 - 3 } & 2.900 & 2.500 & $82,0 \mathrm{a}$ \\
Linhagem 1 & $82,6 \mathrm{Aa}$ & $81,4 \mathrm{Aa}$ & $74,0 \mathrm{c}$ \\
Linhagem 2 & $77,2 \mathrm{Ab}$ & $70,4 \mathrm{Bb}$ & $76,8 \mathrm{~b}$ \\
Linhagem 3 & $79,0 \mathrm{Aab}$ & $74,2 \mathrm{Bc}$ & 77,5 \\
\hline Média & $79,8 \mathrm{~A}$ & $75,2 \mathrm{~B}$ & 7 \\
\hline
\end{tabular}

Médias seguidas por letras diferentes, maiúsculas na mesma linha ou minúsculas na mesma coluna, são estatisticamente diferentes (P<0,05) pelo teste de Newman Keuls

Tabela 4 - Herdabilidades e correlações genéticas para pesos corporais nos ambientes 1 e 2 em três linhagens de codornas de postura

\begin{tabular}{|c|c|c|c|c|c|c|}
\hline \multirow[b]{3}{*}{ Linhagem } & \multirow[b]{3}{*}{ Ambiente } & \multirow[b]{3}{*}{ Característica } & \multirow{2}{*}{\multicolumn{3}{|c|}{$\begin{array}{c}\text { Correlação genética } \\
\text { Ambiente } 1\end{array}$}} & \multirow[b]{3}{*}{$h^{2}$} \\
\hline & & & & & & \\
\hline & & & PC70 & PC100 & PC130 & \\
\hline \multirow[t]{6}{*}{1} & 1 & PC70 & - & - & - & 0,71 \\
\hline & & PC100 & - & - & - & 0,56 \\
\hline & & PC130 & - & - & - & 0,52 \\
\hline & 2 & PC 70 & 0,80 & 0,78 & 0,73 & 0,36 \\
\hline & & PC100 & 0,81 & 0,68 & 0,81 & 0,54 \\
\hline & & PC130 & 0,78 & 0,79 & 0,71 & 0,42 \\
\hline \multirow[t]{6}{*}{2} & 1 & PC70 & - & - & - & 0,37 \\
\hline & & PC100 & - & - & - & 0,88 \\
\hline & & PC130 & - & - & - & 0,82 \\
\hline & 2 & PC70 & 0,70 & 0,71 & 0,70 & 0,34 \\
\hline & & PC100 & 0,76 & 0,78 & 0,79 & 0,52 \\
\hline & & PC130 & 0,61 & 0,67 & 0,64 & 0,68 \\
\hline \multirow[t]{6}{*}{3} & 1 & PC70 & - & - & - & 0,78 \\
\hline & & PC100 & - & - & - & 0,85 \\
\hline & & PC130 & - & - & - & 0,76 \\
\hline & 2 & PC70 & 0,90 & 0,94 & 0,92 & 0,80 \\
\hline & & PC100 & 0,94 & 0,93 & 0,94 & 0,88 \\
\hline & & PC130 & 0,91 & 0,92 & 0,93 & 0,72 \\
\hline
\end{tabular}

PC = peso corporal aos 70, 100 e 130 dias de idade.

Ambientes 1 e 2: aves alimentadas com rações contendo 2.900 e 2.500 kcal de energia metabolizável, respectivamente. 


\section{Conclusões}

A redução na energia metabolizável, de forma geral, acarreta redução na postura, porém uma das linhagens mantém o mesmo nível de produção. A presença da interação genótipo $\times$ ambiente indica que a seleção praticada nas aves alimentadas com ração contendo nível de energia recomendado pode não resultar em ganhos genéticos na descendência alimentada com rações com deficiência de energia. Todavia, a existência de variabilidade genética quando as aves são alimentadas com rações menos energéticas permitiria a seleção para obter aves produtivas, porém com menor exigência em energia.

\section{Agradecimentos}

À Coordenação de Aperfeiçoamento de Pessoal de Nível Superior (CAPES) e ao Conselho Nacional de Desenvolvimento Científico e Tecnológico (CNPq), pelo suporte financeiro. À Universidade Estadual de Maringá, aos colegas de curso Juliana B. Toledo, André Hidalgo, Andréia Michelli, Thais Quadros e a todos que colaboraram direta ou indiretamente para a realização deste trabalho.

\section{Literatura Citada}

FALCONER, D.S. Introdução à genética quantitativa. 1.ed. London: Longman, 1987. p.279.

GIANOLA, D.; FERNANDO, R.L. Bayesian methods in animal breeding theory. Journal Animal Science, v.63, p.217-244, 1986.

MIELENZ, N.; NOOR, R.R.; SCHUELLER, L. Estimation of additive and non-additive genetic variances of body weight, egg weight and egg production in quail, using animal models. In: WORLD'S POULTRY CONGRESS, 22., 2004, Istanbul. Proceedings... Istanbul: Turkey. World's Poultry Congress \& Exibition, [2004]. (CD-ROM).

MINVIELLE, F. Genetics and breeding of japanese quail for production around the world. In: ASIAN PACIFIC POULTRY CONGRESS, 6., 1998, Nagoia. Proceedings... Nagoia: Japan Poultry Science Association, 1998. p.122-127.

NATIONAL RESEARCH COUNCIL - NRC. Nutrient requirements of poultry. 9.ed. Washington, D.C.: National Academy Press, 1994. p.156.

ÖZDEMIR, D.; AKSIT, M. Estimations of genetic parameters of some egg quality characteristics of Japanese quails (Coturnix coturnix japonica) at different ages. In: WORLD'S POULTRY CONGRESS, 22., 2004, Istanbul. Proceedings... Istanbul: World's Poultry Congress \& Exibition, [2004]. (CD-ROM).

$\mathrm{R}$ Development Core Team [2004]. R: A language and environment for statistical computing. Vienna, Austria: R Foundation for Statistical Computing, 2004. Disponível em: $<$ http://www.r-project.org>. Acesso em: 1/9/2006.

Van TASSEL, C.P.; Van VLECK, L.D. A manual for use of MTGSAM. A set of FORTRAN programs to apply Gibbs sampling to animal models for variance component estimation [DRAFT]. Lincoln: U.S. Departament of Agriculture, Agricultural Research Service, 1995. 86p. 